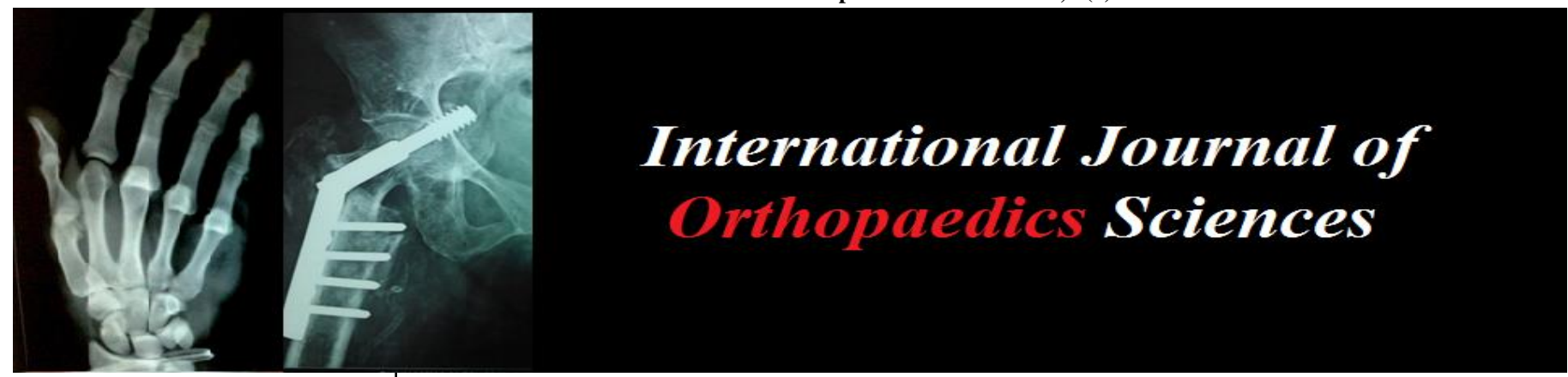

ISSN: $2395-1958$

IJOS 2018; 4(3): 150-152

(C) 2018 IJOS

www.orthopaper.com

Received: 27-05-2018

Accepted: 28-06-2018

Yusuf N

Department of Surgery, Kaduna

State University Teaching

Hospital, Kaduna, Nigeria

Amupitan I

Department of Orthopaedics, Jos

University Teaching Hospital

Jos, Nigeria

\section{Ode MB}

Department of Orthopaedics, Jos University Teaching Hospital

Jos, Nigeria

\section{Amupitan FA}

Department of Anaesthesia, Jos

University Teaching Hospital

Jos, Nigeria

Ngyal TE

Department of Orthopaedics, Jos

University Teaching Hospital

Jos, Nigeria

\section{Treatment of unstable proximal femoral fractures using proximal femoral locked compression plates our experience}

\author{
Yusuf N, Amupitan I, Ode MB, Amupitan FA and Ngyal TE
}

DOI: https://doi.org/10.22271/ortho.2018.v4.i3c.27

\section{Abstract}

Introduction: Proximal femoral fractures account for about 10 to $34 \%$ of all hip fractures with bimodal age distribution and different mechanisms of injury. Older patients sustain low velocity trauma while in younger patients these fractures are from high energy trauma. Early surgical intervention is recommended for most of these patients to reduce the complications associated with prolonged immobilization. The locking compression plate is used for angular-stable plating for the treatment of complex comminuted and osteoporotic fractures. This type of internal stabilization may be the choice for subtrochanteric or transverse intertrochanteric fractures.

Objective: The study aimed to report the outcome of management of unstable proximal femoral fractures which was managed using proximal femoral locked compression plate in our setting.

Method: A retrospective study of all conservative patients managed at two centres in Nigeria. The Jos University Teaching Hospital, Jos, Plateau State and the Barau Dikko Teaching Hospital, Kaduna State University Teaching Hospital Kaduna. A structured Proforma was used to retrieve information from the hospital records and operation notes of patients that where fixed with PF-LCP.

Results: A total of 25 fractures in 25 patients where studied, 17 males and 8 females with a male female ratio of $2: 1$. The patient age ranged between 20 to 88 years. Road traffic accident was the commonest etiologic agent account for $73.9 \%$ of the cases and the remaining $26.1 \%$ was due to domestic falls at home. $43.8 \%$ of the patients presented 12 weeks after the injury, $25.0 \%$ of them between 4 to 12 weeks of injury and $31.2 \%$ presented within 4 weeks of the injury. The fractures were intertrochanteric in $16.0 \%$ of the patients and sub trochanteric in $84.0 \%$. The average duration of union as evidenced by bridging callus in at least 3 cortices radiologically was 15.4 weeks. 23 of the patients went on to unite without any complication one had implant failure (screw breakage) due to premature full bearing for which additional surgeries where done while another had an implant infection.

Conclusion: Proximal locked compression plating for proximal femoral fractures is a useful alternative based on its anatomic design for proximal femoral fractures in which could be due to osteoporosis especially in elderly patients.

Keywords: Proximal femoral plate, experience, proximal femoral fractures

\section{Introduction}

Proximal femoral fractures account for about 10 to $34 \%$ of all hip fractures with bimodal age distribution and different mechanisms of injury ${ }^{[1-3]}$. Older patients sustain low velocity trauma while in younger patients these fractures are from high energy trauma ${ }^{[4]}$. The fractures in the elderly patients are usually associated with severe background osteoporosis ${ }^{[2]}$. Early surgical intervention is recommended for most of these patients to reduce the complications associated with prolonged immobilization ${ }^{[5]}$.

The management of this fracture is challenging due to the inherent instability of the fracture pattern and the muscular forces acting on the proximal and distal fragments, however the treatment of fractures of the proximal femur has evolved significantly over recent years. The most recent advance is the proximal femoral locking compression plate. The locking compression plate was introduced in the 21 st century as a new implant that allows angularstable plating for the treatment of complex comminuted and osteoporotic fractures ${ }^{[6-10]}$.

Over the years there has been a paradigm shift in the principles of management of these fractures from rigid anatomic reduction to relative biologic fixation which preserves the

\section{Correspo
Yusuf N}

Department of Surgery, Kaduna

State University Teaching

Hospital, Kaduna, Nigeria 
vascularity of bone fragments and enhances their callus forming abilities.

The $4.5 / 5.0 \mathrm{~mm}$ proximal femoral locking plate is a limited contact angular stable construct designed specifically for fractures in the proximal femoral region, unlike conventional compression plate, the screw head locks into the plate to create an angular stable construct. The PF-LCP also functions as an internalised external fixator, and close bone to bone contact is not needed, minimises periosteal stripping with better healing outcome. The proximal lateral locking compression plate of the femur (PFLCP) may provide tensioning of the lateral wall of the trochanter and prevent lateral migration of the proximal fragments. This type of internal installation may be the choice for sub trochanteric or transverse intertrochanteric fractures $[3,6]$ The angle blade plating can achieve angular stability but often requires a wide exposure and precise plate positioning with little margin for error.

\section{Method}

A retrospective study of all patients admitted to the hospital with proximal femoral fracture managed by the use of PFLCP between June 2012 and December 2015. A structured proforma was used to obtain the data from the file and operation records.

Surgery was performed under spinal anaesthesia except where otherwise indicated. Intravenous ceftriaxone 1 gram was given as prophylactic antibiotics, with patient lying in the lateral position. The fracture was exposed via direct lateral approach, straight incision from the greater trochanter extending about $10 \mathrm{~cm}$ distally. The proximal fragment is first fixed to the plate and then reduced appropriately and held with reduction clamps. After ensuring perfect anatomic placement of the plate to the proximal fragment, a $2.5 \mathrm{~mm}$ drill tip guide wire is inserted through a wire sleeve that is threaded to a most proximal hole at a predetermined 95 degree angle. A second guide wire is also through the second hole in a 120 degree angle and the third at 135 degree angle. The plate was then distally fixed with mixture of locking and cortical screws.

After securing haemostasis wound was irrigated with normal saline and drain inserted and wound was closed in layers and pressure dressing applied.

Drain was removed after 48hours. Patient was mobilized on crutches from non-weight bearing to partial weight bearing and then full weight bearing where there is evidence of both clinical and radiological union.

Patients with open fractures, active or passive infection and pathological fractures other than osteoporosis were excluded from the study.

\section{Results}

A total of 24 patients where studied 14 males and 2 females making a male female ratio of $7: 1$. The patient age ranged between 20 to 80years. The distribution pattern is shown in table1.

Table 1: Age Distribution (Years)

\begin{tabular}{|c|c|}
\hline Age & Frequency \\
\hline $20-30$ & 3 \\
\hline $31-40$ & 6 \\
\hline $41-50$ & 8 \\
\hline $51-60$ & 4 \\
\hline $61-70$ & 0 \\
\hline $71-80$ & 4 \\
\hline
\end{tabular}

Road traffic accident was the commonest etiologic agent accounting for $87.5 \%$ of the cases and the remaining $12.5 \%$ was due to domestic falls at home. $43.8 \%$ of the patients presented 12 weeks after the injury, $25.0 \%$ of them between 4 to 12 weeks of injury and $31.2 \%$ presented within 4 weeks of the injury. The fracture pattern was Trans trochanteric in $25 \%$ of the patients, subtrochanteric in $50.0 \%$ of the patient and $25.0 \%$ where communinated subtrochanteric fractures. The average duration of union as evidenced by bridging callus in at least 3 cortices radiologically was 15.4 weeks. The distribution is shown as in table 2 .

Table 2: Time Taken For Clinical and Radiologica L Union (Weeks)

\begin{tabular}{|c|c|}
\hline Duration in weeks & Number of patients \\
\hline $12-18$ & 17 \\
\hline $19-24$ & 7 \\
\hline $25-30$ & 1 \\
\hline
\end{tabular}

14 of the patients went on to unite without any complication. One had implant failure (screw breakage) due to premature full weight bearing for which additional surgeries where done while another had an implant infection.

\section{Discussion}

As in most cases of trauma males predominate which was noticed in our series with a ratio $7: 1$, this is due to the fact that men are more active, have to cater for their family needs and as such are exposed to various hazards such as Road traffic accident. It's also important to note that women, especially the older age group are susceptible to hip fractures due to osteoporosis but this was not significant in our own study which accounted for only $12.5 \%$. Late presentation was the norm in our study $68.8 \%$ which is similar to findings in other studies within our environment which can be accounted for by the practice of traditional bone setters which is also associated with high complication rates. On account of the delayed presentation, minimally invasive procedures such as closed proximal femoral plating are difficult to carry out. These minimally invasive procedures are usually associated with shorter operation time less complication and better outcome. The outcome from our study was good and could be comparable to other sturdies but a definitive conclusion cannot be drawn from this study because of the relatively small sample.

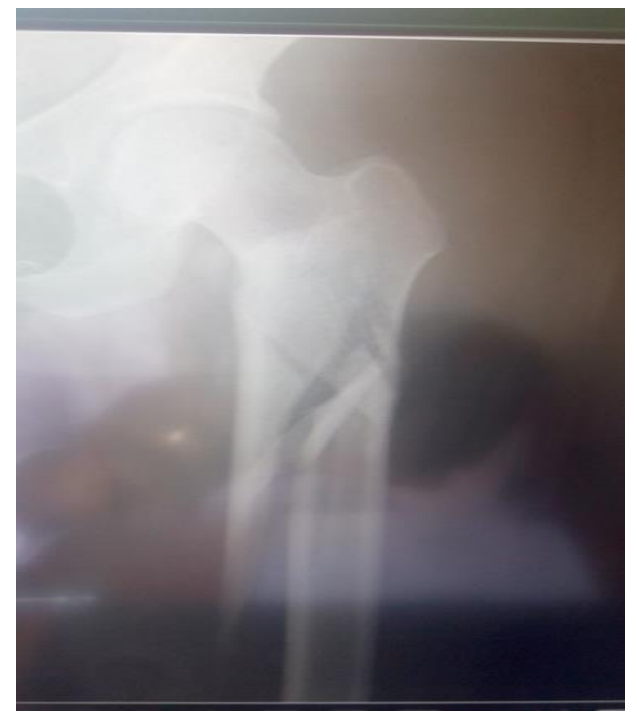

Fig 1: preoperative Xray 


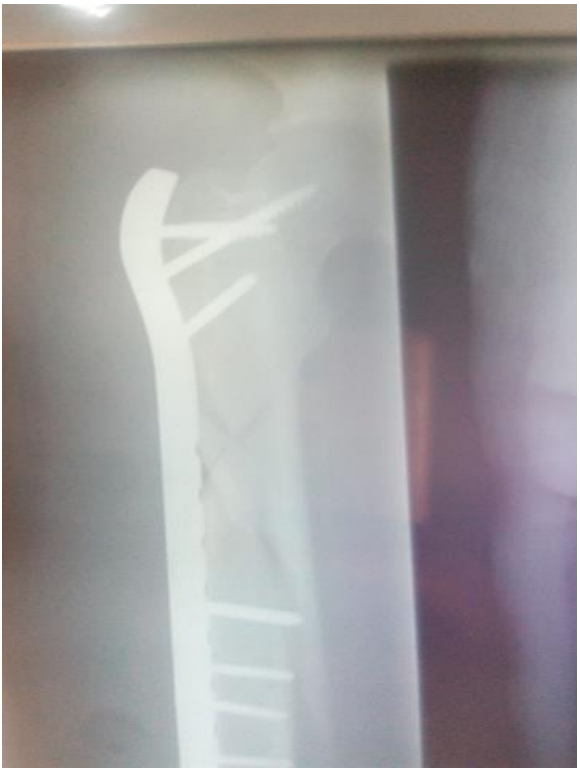

Fig 2: post-operative $\mathrm{x}$ ray

\section{Conclusion}

Proximal locked compression plating for proximal femoral fractures is a useful alternative based on its anatomic design for proximal femoral fractures (sub trochanteric and intertrochanteric) fixation in a poor resource centre without image intensifier where appropriately indicated.

\section{Reference}

1. Anyaehie UE, Ejimofor OC, Akpuaka FC, Nwadinigwe CU. Pattern of femoral fractures and associated injuries in a Nigerian tertiary trauma centre. Niger J Clin Pract 2015; 18:462-6.

2. Gakuu LN. The challenge of fracture management in osteoporotic bones: EAOJ; 2010, 4

3. $\mathrm{Hu}$ Sun-Jun, Zhang Shi-Min, Yu Guang-Rong. Tratamento das fraturas femorais subtrocantéricas com placas de bloqueio lateral da parte proximal do fêmur. Acta ortop. bras. [Internet]. 2012 Dec [cited 2017 Nov 21]; 20(6):329-333. Available from: http://www.scielo.br/scielo.php?script=sci_arttext\&pid=S 1413-78522012000600003\&lng=en. http://dx.doi.org/10.1590/S1413-78522012000600003

4. JB Sié Essoh, Kodo M, Traoré A, Lambin Y. Surgical treatment of trochanteric fractures: An Ivorian experience: Nigerian journal of surgical Research 2005; 7(1, 2):187-190

5. Stern R. Are there advances in the treatment of extracapsular hip fractures in the elderly? Injury. 2007; 38(Suppl 3):S77-87.

6. Hasenboehler EA, Agudelo JF, Morgan SJ, Smith WR, Hak DJ, Stahel PF. Treatment of proximal femoral fracture fractures with the proximal femur locking compression plate. Orthopedics. 2007; 30(8):618-23.

7. Egol KA, Kubiak EN, Fulkerson E, Kummer FJ, Koval KJ. Biomechanics of locked plates and screws. J Orthop Trauma. 2004; 18:488-493.

8. Frigg R. Development of the Locking Compression Plate. Injury. 2003; 34(suppl 2):6-10.

9. Gautier E, Sommer C. Guidelines for the clinical application of the LCP. Injury. 2003; 34(suppl 2):B63B76.

10. Sommer C, Gautier E, Muller M, Helfet DL, Wagner M. First clinical results of the Locking Compression Plate (LCP). Injury. 2003; 34(suppl 2):B43-B54.
11. Wagner M. General principles for the clinical use of the LCP. Injury. 2003; 34(suppl 2):B31-B42.

12. Injury journal. 2011; 42(11):1294-1299

13. Glassner, Philip J MD, Tejwani, Nirmal CMD. Failure of Proximal Femoral Locking Compression Plate: A Case Series. Journal of Orthopaedic Trauma. 2011; 25(2):7683 doi: 10.1097/BOT.0b013e3181e31ccc 